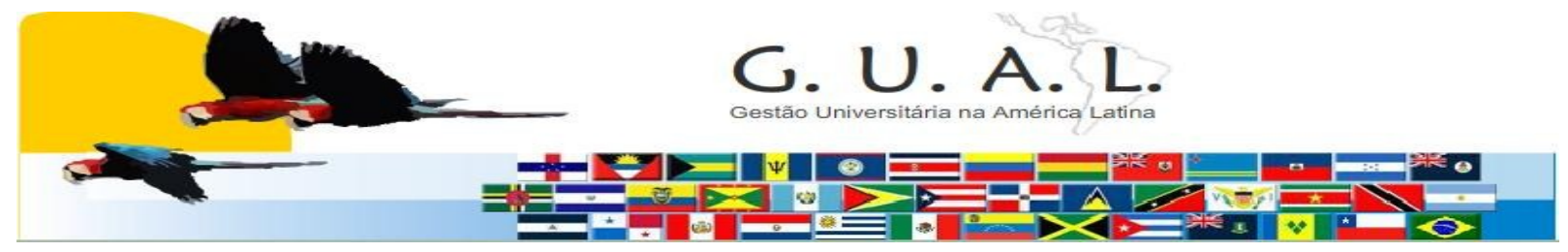

ISSN 1983-4535

\title{
A IMPLANTAÇÃO DO PLANEJAMENTO ESTRATÉGICO EM ORGANIZAÇÕES COMPLEXAS: O CASO DA UNIVERSIDADE DO ESTADO DE SANTA CATARINA
}

\section{IMPLEMENTATION OF STRATEGIC PLANNING IN COMPLEX ORGANIZATIONS: THE CASE OF THE UNIVERSIDADE DO ESTADO DE SANTA CATARINA}

Mariana Oliveira Moritz, Mestranda Universidade Federal de Santa Catarina - UFSC marimoritz@hotmail.com

Gilberto de Oliveira Moritz, Doutor Universidade Federal de Santa Catarina - UFSC gomoritz@cse.ufsc.br

Michelle Bianchini de Melo, Mestranda Universidade Federal de Santa Catarina - UFSC chelymelo@gmail.com

Flora Moritz da Silva, Mestranda Universidade Federal de Santa Catarina - UFSC

Recebido em 12/janeiro/2011 floramds@gmail.com

Aprovado em 16/abril/2012

Sistema de Avaliação: Double Blind Review

Esta obra está sob uma Licença Creative Commons Atribuição-Uso. 


\title{
RESUMO
}

O presente artigo busca descrever como prática de gestão, a implantação do planejamento estratégico em uma organização complexa, no caso o Plano 20, cujo desenvolvimento e ação ocorrem na Universidade do Estado de Santa Catarina (UDESC). O referencial teórico buscou entrelaçar aspectos da complexidade da universidade enquanto organização e os processos que abarcam gestão e planejamento estratégico pertencentes a ela, dando vistas a caracterização da UDESC e do Plano 20. Esta pesquisa de caráter descritivo e qualitativo culminou na percepção da implantação da ferramenta estratégica como ação de difícil adesão interna, mas que no entanto motiva aqueles que acreditam ser esse o primeiro passo para a realização de mudanças na universidade.

Palavras-chave: Organizações complexas. Universidade. Planejamento estratégico. UDESC. Plano 20.

\begin{abstract}
This article aims to describe how management practice, the implementation of strategic planning in a complex organization in the event the Plan 20, whose development and action occur at the Universidade do Estado de Santa Catarina (UDESC). The theoretical aspects of complexity sought to weave the university as an organization and processes covering strategic management and planning pertaining to it, giving views of the characterization UDESC and Plano 20. This research was a descriptive and qualitative perception culminated in the implementation of the action as a strategic tool of difficult internal membership, but who nevertheless motivates those who believe that this is the first step to making changes at the university.
\end{abstract}

Keywords: Complex organizations. University. Strategic planning. UDESC. Plano 20. 


\section{INTRODUÇÃO}

As universidades, assim como outras organizações, encontram-se em um processo de mudança e inovação, principalmente no que tange o período pós LDB (Lei de Diretrizes e Bases da Educação) de 1996 e as reformas governamentais realizadas na primeira década deste século. Essas mudanças permitiram a expansão, trouxeram um novo horizonte para a internacionalização, inserção social e para os mecanismos de avaliação, tanto dos alunos como das próprias universidades.

Percebe-se que nesse processo a universidade passa a olhar além de seus muros. A Pós-Graduação ocupa lugar de destaque na instituição, a aliança empresa-universidade passa a funcionar com laços mais estreitos, o financiamento de pesquisa ocorre advindo de diferentes fontes, na graduação a internacionalização e as parcerias com outros países está mais acessível, materiais, acesso aos livros e comunicação acompanham a velocidade das novas mídias digitais em virtude da Educação a Distância.

Apesar das gradativas mudanças, muito ainda há de ser modificado. Quando se fala de universidade não podemos esquecer da educação brasileira e que uma está vinculada ao sucesso da outra. A universidade evolui à medida que a educação básica e fundamental ganha espaço, importância, alunos e respeito do governo e sociedade.

Apesar do envolvimento com o exterior, é notável a dificuldade que os gestores têm dentro das universidades em buscar iniciativas de mudança e inovação, seja no quadro de funcionários ou em novas estratégias de gestão. Nesse contexto, é que se faz válido o processo de (re) pensar as práticas e modelos de gerir as organizações universitárias.

Para Colossi apud Rizzatti e Rizzatti Jr. (2004), a velocidade com que ocorrem as transformações globais no mundo moderno é acelerada nos últimos anos. A partir dessas transformações, começam a ser feitas análises e reflexões, não só em relação a sua natureza, mas também sobre suas perspectivas. O processo de mudança é bastante complexo, pois vivese um momento de mudança de rumos no mundo dos negócios, ambiental, político e inovações tecnológicas. A sociedade apresenta diferentes características, objetivos e crenças do conceito de homem e de seus valores, esses são exemplos que sinalizam a necessidade de estabelecer os novos paradigmas que consideram o homem como elemento central deste cenário de transformações globais dentro das instituições/organizações.

As organizações entendem hoje o valor humanístico e que o sucesso de cada uma está na forma de gerir as pessoas que dela fazem parte. Hoje o fato de gerir pessoas e estabelecer 
novas estratégias é um dos cargos de maior responsabilidade dentro das organizações, se a organização possuir uma equipe bem coordenada e preparada para os desafios, com certeza terá grandes chances de sucesso.

Mas na universidade, a realidade dessa rápida ação não se aplica, já que se trata de uma instituição com diferentes objetivos, multi disciplinar, gestora de recursos intelectuais, gera e dissemina conhecimento, propaga debates, arte e música, enfim os objetivos da universidade são extensos e complexo por isso a dificuldade em geri-la.

Brotti et al. (2000, p. 9) afirmam, no entanto, que:

Paradoxalmente as organizações acadêmicas são as que apresentam mais dificuldades em introduzir mudanças internas, incorporar novas tecnologia e redefinir seus processos e produtos. Normalmente, elas atuam dentro de um quadro referencial burocrático-legal, onde o governo exerce a influência e o controle.

A elaboração de estratégias e incorporação de novas posturas dentro da universidade é um processo lento, a participação e aderência nestas situações geralmente não atraem a todos como deveria, são processos involuntários e não obrigatórios, a vontade de mudar não parte de um todo e sim de uma minoria que anseia pela mudança.

Para Valentim (2007):

As organizações em sua complexidade requerem um continuum informacional, que apoiem suas estratégias, suas ações e a construção de conhecimento corporativo. Sendo assim, a informação deve ser reconhecida como elemento chave para o desenvolvimento organizacional.

Para Rizzatti e Rizzatti Jr. (2004), as universidades se caracterizam como um agrupamento de indivíduos, submetido a regras e a uma estrutura de posição que define as relações entre eles. Estas regras e estruturas são estabelecidas de forma deliberada e intencional. Suas estruturas são padronizadas nacionalmente segundo os preceitos da lei, e não levam em conta as necessidades de cada instituição, as características que englobam as questões regionais e as mudanças exigidas pela sociedade local, e esses fatores acabam por ocasionar distorções na definição de seus objetivos, na sua gestão e na política de pessoal.

Por essas características, a universidade geralmente não aceita a aplicação de técnicas usadas com sucesso em outras organizações, afinal a universidade é vista como um tipo diferente de ambiente e organização, mas que está em constante aprimoramento, e para isso exige de seus gestores, servidores técnicos e docentes, capacidade de ação, de mudar, de aplicar diferentes estratégias, de vencer a cultura enraizada da repetição de antigas técnicas. 
Para Lopes e Bernardes (2010) o problema de estruturação administrativa das Instituições de Ensino Superior reside na busca de um modelo que atenda às suas especificidades, que são originadas no pluralismo político e ideológico, que produz divergências, inclusive, no entendimento do projeto de universidade.

Em virtude destas tendências e dos novos desafios que a universidade brasileira enfrenta, faz-se pensar na reformulação da sua função e missão, definir novos objetivos e estabelecer novas prioridades para o futuro, desencadeando um processo de mudanças e desenvolvimento.

No contexto de mudança atual o presente artigo busca descrever a prática do planejamento estratégico como ferramenta auxiliadora na gestão da universidade, no caso, a UDESC. Para atingir o objetivo proposto, este artigo está estruturado em seis seções, incluída esta seção inicial. A segunda é representada pelo referencial teórico-empírico, em que são apresentados os conceitos relativos a universidades como organizações complexas, a gestão na universidade, planejamento estratégico e resistência à mudança na universidade. $\mathrm{Na}$ terceira seção são apresentadas as condutas metodológicas que foram empregadas na pesquisa. A quarta seção corresponde ao histórico da UDESC e a utilização do Plano 20 e seus resultados. Por fim, uma seção em que são apresentadas as conclusões do artigo e na sequência as referências utilizadas.

\section{ORGANIZAÇÕES COMPLEXAS : AS UNIVERSIDADES}

As universidades são caracterizadas como organizações complexas, de personalidade jurídica própria e responsabilidade pública, com características comuns a outras burocracias. As universidades possuem cargos hierarquizados com conduta regulamentada através de normas, autoridade do tipo burocrática em alguns setores e atos administrativos formulados por escrito (LOPES; BERNARDES, 2010).

Pela complexidade da universidade, a LDB entende que universidades são instituições pluridisciplinares de formação dos quadros profissionais de nível superior, de pesquisa, de extensão e de domínio e cultivo do saber humano, conforme disposto no Art. 52 da Lei de Diretrizes e Bases da Educação Nacional (LDB) - Lei no 9.394, de 20/12/1996.

Segundo Morin apud Audet e Maloin (1986), de um modo geral, pode-se dizer que quanto mais uma organização é complexa, mais ela admite a desordem. Essa condição lhe fornece vitalidade, porque os indivíduos são capazes de tomar iniciativas para regular esse ou aquele problema sem ter de consultar a hierarquia central. 
Contudo para os autores, o excesso de complexidade pode desestruturar a organização. Se uma determinada organização só tem liberdades e pouca ordem ela acaba se desintegrando, a menos que exista junto com essa liberdade uma profunda cumplicidade e solidariedade entre seus membros. A solidariedade vivida é a única circunstância que permite o aumento da complexidade. Por fim, as redes informais, as resistências colaboradoras, as autonomias, as desordens, são ingredientes necessários à vitalidade das organizações.

Para Borges (2009) as universidades se encaixam nesta característica, pois:

"A teoria da complexidade estuda os sistemas adaptativos complexos, ou
seja, estuda qualquer conjunto de elementos ou agentes que interagem
dinamicamente entre si reproduzindo seu próprio comportamento" (apud
Corrêa, 2009). Edgard Morin, pensador francês e estudioso sobre o assunto,
contextualiza a complexidade defendendo a interligação de todos os
conhecimentos, ou seja, de que tudo no universo está interligado. Estudar a
teoria pode significar entender como sistemas complicados podem gerar um
comportamento simples, além de compreender que o universo é formado por
sistemas que se adaptam apesar de complexos ou por que não, apesar de
diferentes, gerando um equilíbrio.

Perkins apud Leitão (1985) considera a universidade uma organização complexa não só pela sua condição de instituição especializada, mas principalmente pelo fato de executar tarefas múltiplas, onde cada tarefa (relacionada com ensino, pesquisa e extensão) tem uma metodologia de trabalho que lhe é própria, diferente daquela desenvolvida pelas outras organizações.

Para Demo (1991) uma universidade moderna se define como instituição onde se aprende a aprender, que tem sua importância à medida que representa o desafio atual da educação sendo o instrumento central da modernidade, da sociedade e da economia, admitindo-se que a educação seja fator primordial desse processo, na condição de geradora da capacidade de criar tecnologias inovadoras e alternativas, muito embora tal visão possa recair na prepotência da técnica sobre a política.

A complexidade é um paradigma que permeia o pensamento do saber não fragmentado, relacional, interdisciplinar e holístico, cuja base de estudo, enquanto teoria permeia uma melhor compreensão dos seres humanos. Nos organismos vivos, a complexidade reflete no entendimento de que o todo está nas partes e a parte está no todo. Assim, ao compreendermos que todas as atividades de uma organização podem ser consideradas "parte" e seu fim o "todo", a complexidade não será tão complicada, mas não deixará de ser complexa (BORGES, 2009). 
Para Rizzatti e Rizzatti Jr. (2004), as organizações universitárias são sistemas sociais altamente dinâmicos e complexos, resultado de muitos conflitos gerados por grupos internos e externos, que nelas atuam e agem em conformidade com seus próprios interesses. Muitos dos conflitos que ocorrem na universidade se originam na complexidade de sua estrutura social, acadêmica, nos objetivos e valores complexos desses grupos divergentes.

Alguns autores caracterizam a universidade de diferentes maneiras apresentadas no quadro a seguir:

\begin{tabular}{|c|c|c|}
\hline BALD & BLAU (1984, p. 11) & 273) \\
\hline $\begin{array}{l}\text { Ao examinar a liderança e as } \\
\text { decisões na organização } \\
\text { universitária, rotulou-a como } \\
\text { uma "anarquia organizada", } \\
\text { onde existe pouca coordenação } \\
\text { e controle e, onde cada } \\
\text { indivíduo é um autônomo } \\
\text { tomador de decisões. }\end{array}$ & $\begin{array}{l}\text { Considera a universidade como uma } \\
\text { burocracia. Diz in verbis: "As } \\
\text { universidades e outras instituições } \\
\text { acadêmicas compõem-se de uma estrutura } \\
\text { administrativa que é fundamentalmente } \\
\text { semelhante à de burocracias } \\
\text { governamentais, firmas privadas e } \\
\text { fábricas, e, sem dúvida, organizações mais } \\
\text { formais". }\end{array}$ & $\begin{array}{l}\text { "As universidades constituem } \\
\text { organizações inconfundíveis, sui } \\
\text { generis, diferentes, que não podem } \\
\text { ser tratadas com as mesmas teorias } \\
\text { nem com as mesmas técnicas com } \\
\text { que se analisam e se estudam as } \\
\text { organizações com fins lucrativos". }\end{array}$ \\
\hline
\end{tabular}

QUADRO 1 Características da Universidade

Fonte: Elaborado pelos autores.

Após os conceitos expostos pelos autores o intuito da gestão na universidade seria de preocupar-se em criar vínculos com a complexidade para melhor entender a organização, os diferentes departamentos, contextos e objetivos, a fim de formar uma gestão plural e participativa ao alcance de todos.

\subsection{A gestão na Universidade}

Simões (2004) afirma que na área da administração universitária, são escassos, os estudos práticos publicados no Brasil, principalmente os referentes à gestão universitária de instituições públicas. É um conhecimento especializado voltado para gestores universitários, em especial, bem como para profissionais da área de Contabilidade, Administração, Economia e Gestão Educacional.

Fala-se muito da universidade em si, estruturas, missão, objetivos, mas pouco são os relatos dos gestores da instituição universitária, suas experiências, suas dificuldades e seus sucessos na literatura brasileira.

Assim como em qualquer outra organização a universidade necessita de gestores capazes de resolver os seus multiobjetivos, ter influência nos processos decisórios, 
conhecimento de educação, leis, recursos humanos, alunos, projetos e enfim, conhecer toda a riqueza de atores existentes no contexto em que atua.

Para Lopes e Bernardes (2010), as decisões na aplicação de estratégias nas universidades brasileiras sofrem influências da estrutura e poder vigentes do Estado ou de grupos de alto escalão nela representados, por isso a preocupação em se ter gestores com bons relacionamentos na comunidade local, governos, lideranças representativas, conselho estudantil, sindicatos e etc.

Para Finger (1993) apud Rizzatti e Rizzatti Jr. (2010), a área da administração universitária preocupa-se com a problemática da gestão organizacional. A administração universitária pode ser classificada em duas modalidades: os serviços administrativos e de infraestrutura (atividade meio) e a prática acadêmica que compreende laboratórios, prática de estágios, professor em sala de aula, etc. (atividade fim). Cada um desses setores da administração educacional constitui um campo específico de trabalho para o profissional da instituição cuja formação exige a aquisição de competências conceituais ou administrativas, técnicas e humanas, que devem sempre caminhar juntas.

Para Meyer (1988), estudioso e um dos precursores a abordar o tema gestão universitária no Brasil, a universidade por suas características peculiares deve ser administrada com diferenciação das outras organizações:

Na prática, percebe-se que a administração de uma organização universitária é algo bastante distinto da administração de uma indústria têxtil, de uma organização bancária, ou mesmo de uma mera instituição pública prestadora de serviços. Nesta perspectiva, a habilidade e o domínio de técnicas administrativas, largamente utilizadas nas empresas, tornam-se inadequadas e ineficazes à realidade universitária (MEYER JUNIOR, 1988, p. 170).

Entretanto para Lopes e Bernardes (2010), apenas o fato de pertencer ao modelo burocrático não seria suficiente para explicar o modo como as políticas são formuladas nas universidades, onde há ocorrência do poder não-formal, baseado no conhecimento especializado. A ignorância desse tipo de poder não-formal, baseado no saber, segundo Tousignant apud Lopes e Bernardes (2010) é causa de muitos dos fracassos no processo de planejamento universitário. Tousignant (1990) considera que a configuração estrutural particular desse tipo de instituição não se estabelece conforme o modelo vertical das empresas em geral. $\mathrm{Na}$ verdade, são pirâmides invertidas onde os docentes estão no alto e os administrados abaixo deles para servi-los. 
Rodriguez (1983), não concorda com o simples fato de aplicar teorias da administração na gestão de universidades, o autor afirma:

Até os dias atuais, tratou-se de aplicar em nossas universidades, de alguma forma, os modelos e as técnicas que aparecem na administração de empresas. (...) Felizmente as coisas vão mudando. As ideias e as sugestões sobre a administração das universidades não têm qualquer valor se não se baseiam na compreensão de sua própria natureza e da complexidade de seu funcionamento (...). As tentativas simplistas, que pretendem instituir mudanças nas universidades como se tratassem de empresas ou de organismos públicos, prestam-lhe um desserviço (RODRIGUEZ, 1983, p. 274).

Rizzatti e Rizzatti Jr. (2004) abordam um pouco das técnicas e do conservadorismo aplicados na hora de gerir a universidade. Os autores, ao citar VAHL (1991), relatam que um dos problemas encontrados na universidade brasileira é o de natureza administrativa e relaciona-se à baixa qualificação de seus dirigentes. A falta de conhecimentos teóricos da função administrativa faz com que a administração das universidades seja desenvolvida de forma empírica, submetendo-a a riscos e ao conservadorismo. Como consequência, seus atos ficam na dependência das circunstâncias cotidianas ou das ordens de outros ocupantes da mesma posição, que passam a exercer as funções administrativas do ponto de vista de suas expectativas pessoais, sem refletirem as definições adequadas para tais funções.

Colocações de Wood Jr. e Caldas (2002, p.81), reafirmam as considerações já citadas: "Diferentes características implicam o uso de diferentes tecnologias. Implicam também o fracasso potencial de tecnologias desenvolvidas em contextos diferentes." Ressaltam ainda: “[...] o ensino e a produção de tecnologia administrativa no Brasil foram moldados com base na importação e difusão maciças de referências, métodos e linguagem estrangeiros, em especial, aqueles anglo-saxões." Assim, não existem atualmente muitos modelos conhecidos desenvolvidos exclusivamente para a gestão de Instituições de Ensino Superior.

Mesmo consciente de que velhos procedimentos não são adequados, não seria o caso de copiar de outros setores modelos bem-sucedidos, porém também inadequados para a educação, pois deve-se considerar as especificidades de cada setor e suas condições locais. Wood Jr. e Caldas (2002, p. 80) ressaltam novamente este aspecto e demonstram a importância da consideração das condições locais para o planejamento:

Pode-se concluir que qualquer atuação em uma Instituição de Ensino que não considere o equilíbrio da especificidade do setor educacional com as técnicas de gestão que poderiam ser utilizadas, tendo como referência algo que seja especialmente desenvolvido para a educação, pode não funcionar. 
Não passariam de um amontoado de procedimentos que só atenderiam às exigências "relâmpago" do Ministério da Educação (MEC), e dificilmente seriam eficientes.

Nesse sentido, a gestão das universidades, requer não apenas bons administradores, mas lideranças que tenham compromisso ético com os valores acadêmicos e legitimidade diante dos vários segmentos da comunidade acadêmica; requer também criatividade e ideias. E a solução não se encontra no imitar modelos, já que, no que se refere às funções da universidade e seu desenvolvimento, para Dias (2003, p. 77) “[...] não há modelos a serem imitados. A universidade do século XXI tem de ser construída pelos elementos que constituem cada sociedade.”.

\subsection{O planejamento estratégico como ferramenta de gestão nas universidades}

As iniciativas governamentais do início deste século, como o Plano de Desenvolvimento Institucional (PDI), trouxeram um novo momento para a realidade das universidades, o de pensar no longo prazo. As universidades começaram obrigatoriamente a visualizar ações para o horizonte estratégico de cinco anos como solicitado pelo MEC através do PDI.

Em virtude desse momento, algumas universidades passaram a apostar nesta ideia e estender seu horizonte estratégico para mais de cinco, criando comissões para a realização do planejamento estratégico em instituições universitárias como auxílio à gestão.

No Estado de Santa Catarina, a exemplo de outras universidades brasileiras, essa realidade está presente em duas universidades públicas, a UDESC, que já possui o seu concretizado, intitulado Plano 20, que será descrito posteriormente neste artigo e a UFSC, que trabalha para formalizar o seu.

Para os gestores destes processos na UFSC e na UDESC, o Planejamento Estratégico pode ajudar não só nos empreendimentos de outros setores (comunidade, organizações, países estrangeiros e expansão), mas também trazer melhorias significativas para a gestão na universidade. Esse planejamento necessita, no momento de sua implantação, de adaptações sucessivas, visto que o setor educacional sofre interferência direta de ações externas como as decisões do MEC. De toda forma, mesmo que essas interferências externas não ocorram, qualquer planejamento para a gestão de um empreendimento não é algo estático. O processo flui, sofrendo diversos tipos de influencia, adaptando-se e moldando-se conforme as necessidades apresentadas. 
Destacando-se o processo de importância do planejamento estratégico e de como este tem sido desenvolvido pelas Instituições de Ensino Superior, deve-se ter cuidado na hora de sua implantação, pois se sabe que o processo de elaboração de um planejamento estratégico é diferente do momento de implantá-lo e que as principais dificuldades aparecem no momento de sua implantação, certamente, a etapa mais difícil nesse processo (PEREIRA, 2010). Na hora de implantar uma estratégia, deve-se considerar a junção entre o planejamento, a supervisão de processos e o gerenciamento de pessoas, visando atingir os objetivos projetados, como colocam Thompson Jr. e Strickland (2002, p. 311): “A implementação da estratégia é principalmente uma atividade orientada para as operações, que giram em torno do gerenciamento de pessoas e processos de negócios". A tarefa é a de converter estratégias em ações, para que os objetivos sejam alcançados.

Para Rocha (2005) que escreveu sobre a implantação do PDI em sua dissertação, podese considerar a relevância desses fatores da mesma maneira na hora da implantação do planejamento estratégico nas universidades:

Uma Instituição de Ensino Superior necessita considerar: a vocação institucional, a história, a experiência acumulada, o histórico; enfim, é preciso cuidar do momento da implantação do PDI, entendendo que determinadas pessoas na IES possuem um valioso conhecimento, na maioria tácito, que poderia contribuir muito para a transição de uma IES que atua sem planejamento para uma IES organizada, atuante de forma planejada. (ROCHA, 2005).

Thompson Jr. e Strickland (2002, p. 313), afirmam que não há um procedimento universal para ser seguido na implantação das estratégias:

[...] cada desafio de implementação de estratégia acontece em um contexto organizacional diferente. Práticas de negócios e circunstâncias competitivas diferentes, ambientes de trabalho e culturas diferentes, políticas diferentes, incentivos de compensação diferentes, diferentes mesclas de personalidades e históricos organizacionais são muito independentes de situação para situação para exigir uma abordagem personalizada para implementação da estratégia.

Por este motivo, Rizzatti e Rizzatti Jr. (2004), afirmam que a função da administração universitária é auxiliar a conduzir a instituição pelo melhor caminho à realização de seus objetivos, sem comprometer o futuro, sem assumir riscos desnecessários. Como detentora da autoridade deliberativa, a direção universitária representa aquilo que a universidade representa, afim de que todos se comprometam com suas metas, seus ideais e haja empatia entre os participantes. 
Bodini (2004) chama a atenção para alguns aspectos na hora da realização do processo de planejamento estratégico em universidades:

a) A metodologia tradicional para o planejamento estratégico é possível de ser implantada em universidades, porém deve-se levar em consideração que as mesmas são sistemas complexos e que muitas vezes adaptações individuais serão necessárias.

b) Se a estrutura e a dinâmica podem ser de livre escolha, o mesmo não se pode dizer do ambiente externo que define a finalidade do sistema. Isto porque a universidade está inserida no macro sistema nação e sua missão (ou finalidade) irá depender dos objetivos nacionais, recursos disponíveis, políticas industriais, tecnológicas, culturais e educacionais do país.

c) Deve-se reconhecer que o principal cliente do sistema é a sociedade, e que seus anseios de eficiência/eficácia devem ser monitorados permanentemente de forma a identificar desvios entre o almejado e o alcançado.

d) As universidades podem dar início ao planejamento estratégico priorizando alguma (s) de suas áreas, como por exemplo: ensino de graduação, e evoluindo gradativamente às outras.

e) Implantar modelo participativo para administrar as mudanças.

f) Transformar o planejamento em administração estratégica. (BODINI, 2004, p.2).

Para que haja compreensão deste processo, o planejamento estratégico deve abranger todos os níveis hierárquicos e toda a comunidade a fim de que fique enraizada a cultura de se planejar constantemente (ARAÚJO, 1996). E, para que isso ocorra, devem ocorrer negociações sobre fins e meios, distribuição de poder e rejeição de pensamentos únicos e absolutos. Mas, "é preciso ter claras as peculiaridades que fazem a universidade diferente de outras organizações e a necessidade de ajustes do instrumento do planejamento estratégico quando de sua utilização em instituições universitárias". (ARAÚJO, 1996, p. 85).

O planejamento universitário não deve se resumir à solicitação de previsão das necessidades humanas, financeiras e materiais junto às unidades acadêmicas e órgãos administrativos. Ele deve ser capaz de questionar e buscar encontrar soluções para os problemas vividos pelas instituições.

Verifica-se assim que a implementação de estratégias de mudanças dependerá do trabalho e envolvimento dos atores, de sua motivação e da supervisão desse trabalho. O setor educacional não pode mais utilizar práticas de atuação arcaicas e totalmente alheias à questão do planejamento, e muito menos ignorar a necessidade de priorizar a gestão de sua Instituição de Ensino. 


\subsection{A resistência à mudança nas universidades}

Muitas tentativas de se implantar o planejamento estratégico nas universidades caem por terra em virtude da resistência enraizada na cultura organizacional no sentido de não aderir/compreender as mudanças. Para Thompson Jr. e Strickland (2002, p. 330): "É imprudência tentar executar uma estratégia nova com uma estrutura organizacional antiga." Conclui-se que o sucesso da implantação do planejamento depende de mudança do modelo mental nas instituições. Wood Jr. (1995) trata a questão da mudança como elemento fundamental de sobrevivência da organização.

Nogueira (2003, p. 146) trata a dificuldade de adesão a novas estratégias como "sofrimento organizacional". Sobre isso afirma:

Creio ser possível associar a este quadro a ideia de "sofrimento", entendendo-a como uma metáfora que sugere a presença de um quadro de ineficácia generalizada, no qual o futuro ficou embaçado, a comunicação está truncada e as decisões são absurdamente custosas e poucos eficazes; por extensão, o clima nas organizações fica marcado pela angústia e pela insatisfação. Trata-se de um quadro que não anuncia o caos nem a impossibilidade de êxito, mas que convulsiona a vida cotidiana, as consciências individuais e as culturas organizacionais.

O autor ainda ressalta que para que esse "sofrimento" seja enfrentado de modo positivo, a organização requer a assimilação de novos hábitos e procedimentos, uma conversão nos conceitos de vida organizada, a recuperação de certas tradições perdidas e, antes de tudo, a produção em série de recursos humanos inteligentes e visão abrangente compatível com sua realidade e daquilo que ela precisa para continuar existindo (NOGUEIRA, 2003).

Sobre a dificuldade de assimilação do novo nas instituições universitária (Valentim, 2007) afirma:

A informação em organizações complexas não é óbvia, não é transparente, não é compreendida por todos os sujeitos que nela atuam, justamente pelas características mencionadas anteriormente. De fato, cada sujeito, nomeará o que para ele é informação. Ai está a complexidade da informação, em um ambiente extremamente complexo. Por isso mesmo, esse objeto (a informação) e os fenômenos relacionados à ele, devem ser foco de estudos, visando conhecer as problemáticas que o envolve.

Na visão de Pettigrew apud Palácio e Almeida (2010), a mudança pode ser vista como um processo organizacional contínuo que ocorre em um dado contexto marcadamente 
histórico, organizacional e econômico-social. Apesar desse caráter, em certos momentos, ela pode ser intencional e radical.

Nogueira (2003) afirma que do mesmo modo que na sociedade e no Estado, a principal tarefa dos dirigentes democráticos e dos recursos humanos "inteligentes" no interior das organizações é de natureza ético-política: construir uma nova racionalidade (crítica e comunicativa, em vez de instrumental), dar impulso a uma reforma cultural, agir não para maximizar o uso da força, a eficiência a qualquer custo ou as razões administrativas, mas para promover a reposição dos pactos básicos de convivência e a formação de novos alinhamentos políticos e intelectuais.

Para Herzog, Gomes e Gianotti (2007), são sabidas as dificuldades que ocorrem em instituições de ensino sem fins lucrativos, quando estas decidem por um processo de mudança, apoiada em teoria e metodologia na área de empresas. Para os autores há um paradoxo, pois a metodologia da mudança é criada dentro das universidades para as organizações de outros setores, por isso não é visto com bons olhos a prática destes conhecimentos dentro da universidade.

Herzog, Gomes e Gianotti (2007), ainda falam sobre a dificuldade da comunicação acadêmica que em diversos momentos serve-se de um ritual complicado para se fazer entender. Em alguns ambientes, "a validade do que se diz depende de quem profere a palavra e do círculo ideológico em que se inscreve esse locutor. Em outros, o que importa é a palavra proferida". (HERZOG; GOMES; GIANOTTI, 2007, p. 72).

Para Esthér e Fonseca (2001) a mudança organizacional é um processo complexo que requer dos seus gestores capacidade de gerenciá-lo constantemente. É necessário compreender as diferentes forças atuantes dentro e fora da instituição, que provocam resistências ou facilidades no contexto em que ocorrem as mudanças. "As forças sociais geralmente se sobrepõem e gerenciá-las é importante para que a elaboração e o processo de implementação de estratégias sejam coerentes com a realidade de cada instituição.” (Esther e Fonseca, 2001, p. 6).

Por todas as afirmações citadas, entende-se que para que qualquer processo de mudança seja implantada dentro de uma IES, esse deve ser primeiramente trabalhado de forma a sensibilizar os atores responsáveis no que se refere ao seu conhecimento, conceitos e objetivos, para que posteriormente a instituição não se depare com barreiras corporativas e reacionárias. 


\section{PROCEDIMENTOS METODOLÓGICOS}

Fazendo referencia ao tipo de estudo, essa pesquisa classifica-se com descritiva e qualitativa visto que teve como objetivos contextualizar, definir, descrever e analisar a gestão em organizações complexas, no caso a iniciativa de implantação do Planejamento Estratégico (Plano 20) na Universidade do Estado de Santa Catarina. Para Triviños (2006) o estudo descritivo busca a descrição exata dos fatos e fenômenos de determinada realidade.

A pesquisa se baseou em relatos dos atores do Plano 20 na UDESC e análise bibliográfica e documental para fundamentar a teoria.

Conforme o pensamento de Gil (2002), uma pesquisa pode ser definida com um procedimento racional e sistemático, que tem como objetivos procurar respostas aos problemas propostos.

Para compreender e atingir o objetivo da pesquisa propõe-se caracterizar as organizações complexas, a gestão na universidade, o planejamento estratégico como ferramenta de gestão nas universidades e a mudança, no referencial teórico do artigo.

Realizou-se um breve histórico da Universidade do Estado de Santa Catarina e do seu Planejamento Estratégico o Plano 20 e, para finalizar, seguem as considerações finais.

\section{UDESC}

O Governo do Estado de Santa Catarina criou, em 1965, a Universidade para o Desenvolvimento do Estado de Santa Catarina (UDESC), concebendo-a como uma instituição vocacionada à preparação dos recursos humanos necessários ao desenvolvimento integral e integrado do Estado.

A criação e a implementação das Unidades de Ensino Superior do Estado foram distribuídas em três regiões (Florianópolis, Joinville e Lages), caracterizando uma política de campi vocacionados, tendo por objetivos:

a) qualificar pedagogicamente para o magistério e para os estudos e pesquisas educacionais, que detectassem e apresentassem soluções aos problemas educacionais;

b) suprir de profissionais qualificados à administração pública e às empresas catarinenses, em processo de expansão e modernização, bem como de estudos e pesquisas visando à modernização da administração e gerência;

c) atender ao crescimento industrial, especialmente no setor metal-mecânico, igualmente carente de recursos humanos especializados;

d) responder a necessidade de se dinamizar e modernizar a agricultura e a pecuária do Estado. 
Em 20 de maio de 1965 o Decreto $n^{\circ} 2.802$ criou a Universidade incorporando as escolas superiores existentes, a saber: Faculdade de Educação (FAED), Escola Superior de Administração e Gerência (ESAG) e a Faculdade de Engenharia de Joinville (FEJ). A FAED foi criada em 1964, visando à qualificação pedagógica para o magistério e o desenvolvimento de estudos e pesquisas educacionais. Em 1965, a ESAG foi fundada destinada a suprir a falta de profissionais qualificados para as empresas catarinenses em processo de expansão. A FEJ foi autorizada a funcionar em 1965.

Logo após, ocorreu a criação de outras unidade, como a Escola Superior de Medicina Veterinária (ESMEVE), autorizada a funcionar em 1972 e a Escola Superior de Educação Física, autorizada a funcionar em 1973.

A partir de 1982, havendo uma nova legislação sobre Universidades, que contemplava a configuração da UDESC, reiniciou-se o trabalho para o seu reconhecimento junto ao CFE, que culminou com a Portaria Ministerial $n^{\circ} 893$, de 11.11.85, publicada no Diário Oficial da União em 26.11.85.

A partir de outubro de 1990, com a Lei no 8.092 de 01.10.90, a Universidade para o Desenvolvimento do Estado de Santa Catarina é transformada em Fundação Universidade do Estado de Santa Catarina (UDESC), fundação pública mantida pelo Estado, vinculada à Secretaria de Educação, com patrimônio e receita próprios, autonomia didático-científica, administrativa, financeira, pedagógica e disciplinar, observada, no que for aplicável, a organização sistêmica estadual. Como ente jurídico próprio goza do princípio constitucional da autonomia universitária.

Com o objetivo de adaptar o seu Estatuto aos princípios e finalidades estabelecidos na Lei de Diretrizes e Bases da Educação Nacional - LDB nº 9.394/96 foi aprovado pelo Decreto $\mathrm{n}^{\mathrm{o}}$ 4.184, de 06 de abril de 2006 e publicado no Diário Oficial do Estado de Santa Catarina $\mathrm{n}^{\mathrm{o}}$ 17.859, de 06 de abril de 2006, o novo Estatuto da UDESC.

Consolidando-se como universidade, a UDESC vem evoluindo do seu objetivo inicial de formar e qualificar recursos humanos para colocar em prática o princípio constitucional da indissociabilidade entre ensino, pesquisa e extensão.

Conforme estabelecido em seu Regimento Geral, artigo 3, "a UDESC está estruturada na forma de multicampi e compreende: a Reitoria, os campi, os Centros, as Unidades Avançadas e os Departamentos”.

A UDESC conta hoje com uma estrutura de 6 campi, distribuídos pelo Estado, 12 Centros, 45 cursos de graduação, 18 cursos de mestrado e 5 cursos de doutorado. 
A UDESC como única universidade estadual de Santa Catarina, procura atender e diminuir as carências das diferentes realidades vistas no Estado. O curso de Engenharia da Pesca, aberto em Laguna, é um diferencial e prova do investimento da Universidade nas necessidades do Estado.

\subsection{O Plano 20}

O Plano 20 surgiu na UDESC através de diversas tentativas fracassadas de se implantar um Planejamento Estratégico na universidade. Na atual administração o Plano 20 antecedeu a posse e foi a meta de número quatro da campanha do atual Reitor Sebastião Iberes Lopes Melo:

"Elaborar um plano de desenvolvimento institucional, contemplando o plano diretor (infraestrutura fisica, equipamentos, transporte, etc) para cada centro, com vista à política de expansão horizontal e vertical da universidade"

Os envolvidos na campanha entendiam que atualmente a UDESC precisa de um planejamento de médio e longo prazo formulando estratégias. O Plano 20 foi concebido com a missão de valorizar as ideias e as contribuições expressas ao longo da história da UDESC. Por exemplo:

I - Resgatou-se a base conceitual do PLAMEG, quando a UDESC foi criada pelo então Governador Celso Ramos (Decreto 2.802 de 20 de maio de 1965); II - Agregou-se subsídios da proposta de reconhecimento (Portaria Ministerial $\mathrm{n}^{\mathrm{o}}$ 893 de 11/11/85);

III - Utilizou-se do Plano de Desenvolvimento Institucional (PDI) de 2003;

IV - Das contribuições iniciais advindas das reuniões do Colegiado de Administração Superior, constituídos pela equipe da reitoria e diretores gerais de centros;

V - Dos Grupos de Trabalhos (GTs) dos Centros;

VI - Dos Subsídios enviados on-line.

O Plano 20 deve ser um plano de supra-gestão:

$\checkmark$ que perpasse mandatos,

$\checkmark$ que despersonalize a gestão,

$\checkmark$ que tenha continuidade,

$\checkmark$ que reflita os anseios da comunidade,

$\checkmark$ que contemple as macro-políticas institucionais

$\checkmark$ que e além de tudo seja um instrumento de gestão e de negociação interna e externa.

Deve ser um plano útil nos diferentes níveis de participação da vida acadêmcia: 
$\checkmark$ PARA A COMUNIDADE INTERNA: seja a referência que oriente as ações a serem desenvolvidas;

$\checkmark$ PARA A SOCIEDADE: seja uma prestação de contas e uma perspectiva de futuro e esperança e espelhe seus anseios;

$\checkmark$ PARA OS GOVERNANTES, NAS DIFERENTES ESFERAS: por um lado seja a prestação de contas, mas por outro, o instrumento para negociar os investimentos com vistas ao seu desenvolvimento.

O Plano 20 foi um processo iniciado em 2004 com reuniões semanais entre os diretores de centro. Após essas discussões foi criada uma comissão para analise inicial do documento em formação. Os atores componentes da comissão eram:

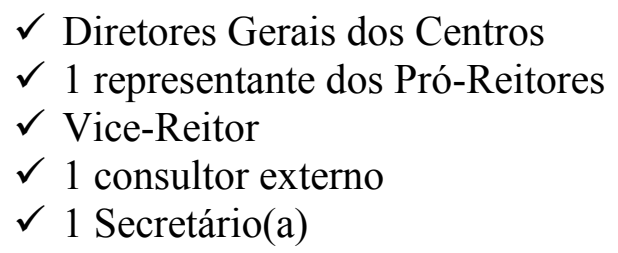

Disponibilizou-se esse documento para a análise dos diretores e em seguida foi realizada a primeira visita aos centros com o documento base. Em 25 de julho de 2005 obteve-se a segunda sistematização e a primeira versão preliminar do Plano 20.

No final deste mesmo ano foi entregue a última versão do Plano 20 ao Magnífico Reitor da UDESC, junto com a disponibilização da sua consulta virtual à comunidade externa e interna.

A finalização seguiu-se de dois procedimentos, a submissão do PLANO 20 à apreciação do especialista na área Prof. Dr. Nério Amboni, para análise crítica, contribuições e prefácio e em 21 de julho de 2006, o Plano foi entregue ao Colegiado de Planejamento da UDESC.

Hoje, a grande dificuldade para que o Plano 20 passe a surtir efeitos na UDESC é sensibilizar os diferentes Centros a terem participação ativa no processo de revisão e construção de suas estratégias, é o que relata Marcus Tomasi, Pró-Reitor de Planejamento e um dos responsáveis pela elaboração do Plano 20. Ele afirma também, que por ser uma instituição pública, esse processo é mais lento do que gostaria e de difícil adesão e compreensão de todos. Hoje em sua opinião o Plano 20 funciona em $20 \%$ de sua totalidade, são políticas para o desenvolvimento do Estado e para ele tem que ser tratado como um documento de continuidade, que dá autonomia para a UDESC e suporte na gestão administrativa. Para Tomasi "é um grande passo para uma instituição pública e universal". 


\section{CONSIDERAÇÕES FINAIS}

Apesar de muito se falar em mudança, as universidades parecem um pouco desencantadas com essa ideia. A comunicação nestas instituições é falha, demorada e as propostas de mudança parecem pouco atrativas.

Mas o desafio de mudança na forma de gerir estas organizações é uma grande imposição neste período de transição de ideias, inversão de valores e futuro incerto.

É difícil constatar de quem é a culpa quando se fala em resistência, se da universidade que foi criada como uma instituição voltada para as elites com controles estatais, ou das técnicas modernas que impregnam as ideias dos empreendedores. Acredita-se que neste caso, os opostos não se atraem e o modelo de clonar as práticas empresariais será fadado ao fracasso.

Mas também se sabe que as práticas de estratégia e mudança nas universidades podem começar de iniciativas de obrigatoriedade como o PDI. Muito se fala desse documento para fins de avaliação ou outro tipo de amarra junto ao MEC, que ele não é flexível, mas, ele é o primeiro passo para a universidade avaliar seu ambiente interno.

Através do PDI a universidade, mesmo que obrigada, começou a planejar e a pensar em um futuro próximo. As comissões foram organizadas de tal maneira que na segunda ou terceira vez da organização deste documento, passou a acontecer um novo olhar no sentido de se pensar o que a instituição deseja ser. Hoje as universidades sabem e têm noção da importância do planejamento estratégico para a vida das organizações.

A universidade junto com seus gestores deve saber planejar, aplicar novas técnicas para poder se apresentar renovada daqui a dez ou vinte anos, para que a sociedade ainda tenha interesse por esta instituição. Mas antes de reaplicar técnicas deve criá-las no intuito de atender a compreensão de todos que passarão por essas mudanças.

Vivemos em um momento que a universidade deixa de ser para poucos e passa a atingir muitos, a universidade virou um centro de oportunidades, além de todos os seus objetivos propostos. Daqui por diante suas ações terão que ser voltadas para o futuro, não importa se é de natureza privada ou pública, o modelo atual, de quadro e giz vai deixar de existir, as novas mídias estão apontando para essa tendência.

O papel de seus servidores técnicos/administrativos e docentes será o de acompanhar essas tendências, conhecer a sua instituição, participar do processo, opinar e incorporar o espírito de mudança. As ferramentas começam a aparecer, como o exemplo do Plano 20, mas 
a missão dos gestores será de fazer o Plano 20 ser incorporado na cultura organizacional e se falando de universidade este processo pode ser longo, por isso como em qualquer outra organização, para que exista sucesso tem que existir a colaboração de todos.

A universidade tem vários caminhos a seguir e muitas dificuldades a serem vencidas, mas um caminho foi proposto pela UDESC, agora é fazer com que a organização acredite no Plano 20 como ferramenta de gestão para o bem, crescimento e mudança da organização.

\section{REFERÊNCIAS}

ARAÚJO, Maria Arlete Duarte de. Planejamento estratégico: um instrumental à disposição das universidades? Revista de Administração Pública, Rio de Janeiro, v. 30, p. 74-86, n. 4, jul/ago, 1996.

AUDET, Michel; MALOIN, Jean-Louis. The Generation of Scientific, Administrative Knowledge. Quebec: Presses de 1'Université Laval, 1986. p. 135-154. Disponível em: $<$ http://www.comitepaz.org.br/Morin5.html>. Acesso em: 02 jun. de 2011.

BALDRIDGE, J. V. Academic governance. California: McCutchan Publishing Corporation, 1971.

BLAU, P. A universidade como organização. In: Revista brasileira de administração da educação, Porto Alegre, v. 2, p. 11, n. 2, jul/dez, 1984.

BRASIL. Lei nº. 9.394/96 - das Diretrizes e Bases da Educação.Lei n ${ }^{\circ} 9.394$ de 20 de dezembro de 1996.

BODINI, Vera Lúcia. Planejamento estratégico em universidades. Disponível em: $<$ http://members.tripod.co.uk>. Acesso em: 02 em jun. de 2011.

BORGES, Vanessa Estela. Teoria da Complexidade e as Organizações: complexas ou complicadas? Disponível em: $<\mathrm{http}$ ://www.artigonal.com/educacao-artigos/teoria-dacomplexidade-e-as-organizacoes-complexas-ou-complicadas-1258109.html>. Acesso em: 02 jun. de 2011.

BROTTI, M. G. A gestão universitária em debate. Florianópolis: Insular, 2000.

DEMO, Pedro. Qualidade e modernidade da educação superior: discutindo questões de qualidade, eficiência e pertinência. Educação Brasileira. Brasília, CRUB, v.13, n.27, 1991.

DIAS, Marco A. R. Espaços solidários em tempos de obscurantismo. In: MORHY, Lauro (Org). Universidade em questão. Brasília: Universidade de Brasília, 2003. p. 55-82.

ESTHÉR, Angelo Brigato; FONSECA, Valkíria Nunes Pereira. Planejamento estratégico numa IFE mineira: o caso da UFJF. Disponível em: $<$ http://www.ichs.ufop.br/conifes/anais/OGT/ogt1701.htm>. Acesso em: 01 jun. de 2011.

GIL, A. C. Métodos e Técnicas de Pesquisa Social. São Paulo: Atlas, 4 ed., 1994. 
HERZOG, Ludger Teodoro; GOMES, Pedro Gilberto; GIANOTTI, Suzana Salvador Cabral. Mudança Organizacional: a experiência da Universidade do Vale do Rio dos Sinos, UNISINOS. In: MURPHY, J. P.; MEYER JUNIOR, Victor. (Orgs.). Liderança e Gestão da Educação Superior Católica nas Américas. Curitiba: Champagnat, 2007. p. 65-103.

LOPES, Luiz Antonio Coelho; BERNARDES, Francesca Ribeiro. Estruturas Administrativas das Universidades Brasileiras. Disponível em: $<$ http://www.ead.fea.usp.br/semead/8semead/resultado/trabalhosPDF/50>. Acesso em: 04 jun. de 2011.

LEITÃO, Sérgio Proença. A questão organizacional na universidade:as contribuições de Etizioni e Rice. Revista de Administração Pública da FGV, Rio de Janeiro, v.4, p. 3-26, n. 19, out./dez, 1985.

MEYER JUNIOR, Victor. Administração Universitária: considerações sobre sua natureza e desafios (1988). In: COLECCION UDUAL. Administracion Universitaria em America Latina: uma perspectiva estratégica. México: UDUAL, 1995.

NOGUEIRA, Marco Aurélio. Organizações Complexas e sociedade da informação:O "sofrimento" como metáfora organizacional. Revista Organizações \& Sociedade, v. 10, p. 145-162, $\quad \mathrm{n}^{\circ} \quad 28, \quad$ set/dez, 2003. Disponível em: $<$ http://labpolitica.files.wordpress.com/2010/01/nogueira-marco-aurelio-organizacoescomplexas-e-sociedade-da-informacao-o-sofrimento-como-metafora-organizacional.pdf $>$. Acesso em: 01 jun. de 2011.

PALÁCIOS, Fernando Antonio Colares; ALMEIDA, Martinho Isnard Ribeiro de. Contexto e Mudança Organizacional na Criação e Implantação de Unidade Universitária: o caso a USP-Leste. Disponível em: $<$ http://www.ead.fea.usp.br/semead/12semead/resultado/trabalhosPDF/648.pdf $>$. Acesso em: 04 jun. de 2011.

PEREIRA. Maurício Fernandes. Planejamento Estratégico: teorias, modelos e processo. São Paulo: Atlas, 2010.

RIZATTI, Gerson; RIZATTI JUNIOR, Gerson. Organização universitária: mudança na administração e nas funções administrativas. Disponível em: $<$ www.inpeau.ufsc.br/.../Gerson\%20Rizzatti\%20-\%20organização\%20universitáriua.doc>. Acesso em: 01 jun. de 2011.

ROCHA, Roberta Muriel Cardoso. Análise do processo de implantação do plano de desenvolvimento institucional: uma contribuição à gestão no ensino superior no Brasil. Dissertação (mestrado), Faculdades Integradas de Pedro Leopoldo, 2005. Disponível em: $<$ http://www.gestaouniversitaria.com.br/index.php?option $=$ com content\&view $=$ article\&id $=2$ 3483:analise-do-processo-de-implantacao-do-plano-de-desenvolvimento-institucional-umacontribuicao-a-gestao-no-ensino-superior-no-brasil\&catid=141:teses-edissertacoes\&Itemid=28>. Acesso em: 04 jun. de 2011 .

RODRIGUEZ, L. L. Novos enfoques sobre administração universitária. Salvador: Gráfica Universitária da UFBA, 1983. 
SIMÃO, Valdecir Antonio. Exame da decisão no ensino superior. Cascavel: Edunioeste, 2004.

THOMPSON, A.; STRICKLAND, A. J. Planejamento estratégico: elaboração implementação e execução. São Paulo: Pioneira, 2002.

TRIVINOS, A. N. S. Introdução à Pesquisa em Ciências Sociais: a pesquisa qualitativa em educação. São Paulo: Atlas, 2006.

VALENTIM, Marta Ligia Pomim. Organizações do conhecimento. Disponível em: $<$ http://www.ofaj.com.br/colunas_conteudo.php?cod=299>. Acesso em: 01 jun. de 2011.

WOOD JR., Thomaz. Mudança organizacional e transformação da função de recursos humanos. São Paulo: Atlas, p. 221-242, 1995.

WOOD JR., Thomaz; CALDAS, M. Antropofagia organizacional e a difícil digestão de tecnologia gerencial importada. [Organizational Anthropophagy and the difficult digestion of imported managerial technology] In: CUNHA, Miguel P.; RODRIGUES, S. B. Manual de estudos organizacionais, Lisboa, RH Ed., v. 1, p. 75-86, 2002. 